\title{
CARACTERIZAÇÃO DA ARBORIZAÇÃO URBANA NO BAIRRO CENTRO DO MUNICÍPIO DE IBITINGA/SP
}

\author{
CHARACTERIZATION OF THE URBAN FORESTRY HELD IN THE NEIGHBORHOOD \\ CENTRO IN THE CITY OF IBITINGA/SP
}

\author{
William Batista Gonçalves ${ }^{1}$, Dorival José Coral ${ }^{2}$, Marcos Vinicius Bohrer Monteiro Siqueira ${ }^{3}$
}

\section{RESUMO}

$\mathrm{Na}$ tentativa de minimizar os impactos gerados pela intensiva urbanização tornou-se comum a prática da arborização urbana, a fim de harmonizar esteticamente o ambiente das cidades. Este trabalho teve por objetivo avaliar os espécimes utilizados na arborização das ruas no bairro Centro do município de Ibitinga/SP. Para isto, foram realizados levantamentos quali-quantitativos em duas avenidas e 12 ruas, perfazendo uma área de 27 quarteirões. Foram amostrados 242 indivíduos, distribuídos em 22 espécies e 15 famílias botânicas. A maioria das espécies presente é exótica $(63,64 \%)$ e as mais frequentes são Ligustrum lucidum $(45,04 \%)$ e Licania tomentosa $(26,45 \%)$. Os resultados apontam baixos valores de diversidade, elevados índices de pragas e alto registro de conflitos com a rede aérea. Verifica-se a necessidade de uma arborização mais diversificada bem como a seleção de espécies através de critérios técnicos na região estudada.

Palavras-chave: Áreas verdes; Espécie exótica; Levantamento quali-quantitativo; Ligustrum lucidum.

\begin{abstract}
In an attempt to minimize the impacts caused by an intense urbanization, the urban forestry has become a common practice, whose intention is to esthetically harmonize the city environment. Thus, this study aimed to evaluate specimens used in urban afforestation in the neighborhood Centro, in the city of Ibitinga/SP. For this, qualitative and quantitative surveys were carried out in two avenues and 12 streets, covering an area of 27 blocks. The sample consisted of 242 individuals that belonged to 22 species and 15 plant families. Most species are exotic (63.64\%) and the most frequent are Ligustrum lucidum (45.04\%) and Licania tomentosa (26.45\%). Data indicate low values of diversity, high rates of pest and conflicts with the air network. There is a great need for a more diverse afforestation as well as for the selection of species through technical criteria in the studied area.
\end{abstract}

Keywords: Green areas; Exotic species; Qualitative and quantitative surveys; Ligustrum lucidum.

Recebido em 01.03.2017 e aceito em 01.08.2017

1 Biólogo. Discente da Universidade Sagrado Coração - USC, na cidade de Bauru - SP. Email: wbg.william@hotmail.com

2 Biólogo. Mestre em Botânica. Professor na Universidade do Sagrado Coração. Bauru/SP. Email: dcoral@usc.br

3 Engenheiro Biotecnólogo. Doutor em Ecologia Aplicada. Professor na Universidade do Sagrado Coração. Bauru/SP. E-mail: mvbsiqueira@gmail.com 


\section{INTRODUÇÃO}

Com as expansões territoriais urbanas ocasionadas por conta do aumento populacional ocorrido nas últimas décadas, o ser humano criou enormes emaranhados de construções em solos impermeabilizados, fazendo surgir a necessidade de criar espaços destinados às áreas verdes e também à arborização de vias públicas (ROCHA; LELES; OLIVEIRA NETO, 2004). A utilização do solo em ambientes urbanos vem, historicamente, alterando a paisagem no Brasil - áreas naturais e fazendas que existiam no início da colonização do país foram transformadas em locais áridos com solo pavimentado (CARDOSOLEITE et al., 2014). Acredita-se que em 2020, 90\% da população brasileira estará vivendo nas cidades (a taxa de urbanização é hoje de 85\%). Ainda assim, a desaceleração urbana já está ocorrendo, segundo relatório Estado das Cidades da América Latina e do Caribe (2012).

A presença de vegetação arbórea no perímetro urbano proporciona benefícios, tais como melhorias no equilíbrio edáfico e microclimático - visto que absorvem grande quantidade de radiação em seus processos biológicos e proporcionam sombreamento e umidade em decorrência da transpiração vegetal, diminuição de poluição sonora e velocidade de ventos (SHAMS; GIACOMELI; SUCOMINE, 2009). Além disso, contribui para a manutenção da avifauna, seja através de pontos de refúgio ou nidificação, traz fluidez estética em meio a grandes construções e, acima de tudo, significativa melhora na qualidade de vida da população (LIMA NETO et al., 2010).

Arborização urbana pode ser caracterizada como sendo o plantio de árvores em parques, praças e calçadas de vias públicas. Entretanto, deve-se manter certa cautela nas escolhas das espécies que irão compor a flora urbana para que não haja conflitos com a infraestrutura urbana como em redes elétricas, tubulações de esgoto e imóveis (SANTOS; JOSÉ; SOUSA, 2013).

O padrão ideal de mudas para o plantio deve conter as seguintes características: sistema radicular bem desenvolvido, rusticidade, bom aspecto fitossanitário e nutricional, tronco retilíneo, copa bem formada, diâmetro mínimo à altura do peito superior ou igual a $3 \mathrm{~cm}$, caule perpendicular em relação ao nível do solo, volume de torrão adequado e isento de plantas daninhas, e também adequação das embalagens como sacos plásticos, latas, balaios e caixotes de madeira (GONÇALVES et al., 2004). Na escolha das espécies deve-se primar por espécies de ocorrência regional, visto que, dentro do paisagismo, a utilização de plantas nativas auxilia na preservação da flora local e reforça a identidade regional (MUNEROLI; MASCARÓ, 2010).

Kramer e Krupek (2012) também apontam que o benefício de um plano de arborização que valorize aspectos paisagísticos e ecológicos com espécies nativas, não se restringe 
apenas à melhora na qualidade de vida da população, mas também ao fato que, por meio dela, pode-se valorizar a identidade biológica da região. Segundo Lima Neto e Biondi (2014), o inventário das espécies arbóreas presentes nas vias urbanas é a maneira mais segura de conhecer este patrimônio da cidade e, através das informações coletadas, direcionar as ações de manutenção, sejam elas tratamentos fitossanitários, remoção, plantios ou replantios.

De acordo com Andreatta et al. (2011) poucas cidades brasileiras possuem um planejamento para suas vias públicas. Acredita-se que seja um consenso geral que as administrações públicas deixam de incluir a arborização em seu planejamento urbano como aparato necessário, fazendo surgir iniciativas particulares sem conhecimento técnico para realização da escolha adequada de espécies e plantio. Essa atitude pode resultar em perda da eficácia da arborização, gerando transtornos às pessoas que circulam pelo passeio público, prejuízo a imóveis e demais áreas da infraestrutura urbana, como rede elétrica e esgoto.

As atividades voltadas para arborização não devem ser realizadas de maneira amadorística, visto que as necessidades urbanas que tentam ser minimizadas através desta prática envolvem aspectos, como avaliações estéticas, ecológicas, socioeconômicas e políticas - afinal, mesmo cidades que possuam políticas voltadas a uma arborização planejada talvez necessitem de correções futuras. Como sublinham Faria, Sousa e Miranda (2014) baseados em outros trabalhos, considerações técnicas sobre qual espécie deve ser plantada em determinado local devem ser priorizadas visto que uma escolha bem feita diminui os custos com manutenção e exalta os benefícios da arborização.

Os resultados obtidos a partir de análises de flora urbana são essenciais para direcionar ações de replanejamentos da arborização urbana, possibilitando a seleção de espécies que sejam compatíveis com a estrutura da cidade e manejo adequado das espécies já existentes no local.

Diante disso, este trabalho teve como objetivo realizar levantamento florístico das ruas do bairro Centro, do município de Ibitinga, analisando as condições fitossanitárias dos espécimes e possíveis conflitos com a infraestrutura urbana.

\section{MATERIAL E MÉTODOS}

\section{Descrição do local}

O presente trabalho foi desenvolvido no município de lbitinga/SP entre março e outubro de 2015. A cidade possui área de $689,391 \mathrm{Km}^{2}$ e população, de acordo com o censo demográfico de 2010, de 53.158 habitantes (IBGE, 2017). Ibitinga está localizada no centro 
geográfico do estado, no Vale médio do Tietê, (coordenadas de $21^{\circ} 45^{\prime} 23^{\prime \prime}$ S e $48^{\circ} 49^{\prime} 08^{\prime \prime}$ O), a $455 \mathrm{~m}$ de altitude e possui solo do tipo argiloso. Segundo Cepagri (2015), o município possui clima do tipo Aw, e de acordo com a classificação de Köppen é caracterizado como tropical chuvoso, com inverno seco e mês mais frio com temperatura média de $18^{\circ} \mathrm{C}$. Durante o inverno, o mês de agosto apresenta os menores índices de precipitação, com médias inferiores a $60 \mathrm{~mm}$.

O bairro Centro do município é caracterizado pela atividade comercial onde se situam diversas lojas de variados seguimentos, principalmente do ramo de enxovais (base da economia local), o que atrai diversas pessoas de cidades da região e também de outros estados como Minas Gerais, Rio de Janeiro, Distrito Federal, entre outros, que vêm em busca dos produtos produzidos, caracterizando-a como uma cidade voltada para o turismo de negócios.

A área delimitada para a amostragem possui um total de 12 ruas e duas avenidas, perfazendo um espaço de 27 quarteirões analisados, sendo que a análise foi restrita apenas ao calçamento urbano. As avenidas em questão são: Avenida Dom Pedro II e Avenida Sete de Setembro e as ruas pertencentes à amostra são: Adail de Oliveira, Bom Jesus, Capitão Simões, Daniel de Freitas, Domingos Robert, Doutor Teixeira, José Custódio, Miguel Landim, Prudente de Morais, Tiradentes, Treze de Maio e Victor Maida perfazendo uma área de aproximadamente $285000 \mathrm{~m}^{2}$ (Figura 1).

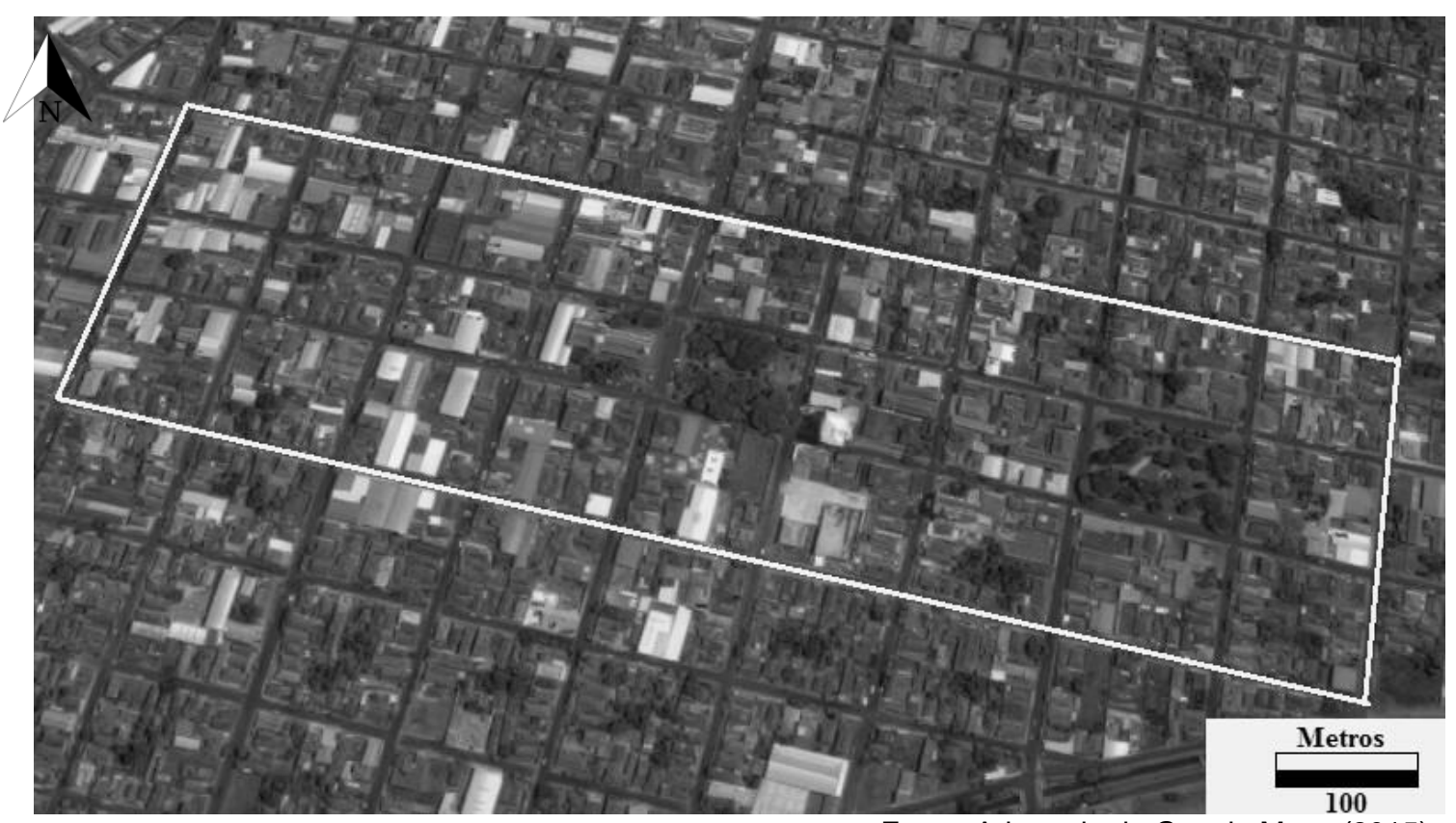

Fonte: Adaptado de Google Maps (2015)

Figura 1. Área de amostragem do bairro Centro, do município de Ibitinga/SP

Figure 1. Sampling area of the neighborhood Centro in the city of Ibitinga/SP 


\section{Coletas de dados}

Foi adotado como critério base o inventário de indivíduos que apresentassem altura igual ou superior a $2 \mathrm{~m}$. Para realização da coleta de dados foi utilizada uma tabela proposta por Silva Filho et al. (2002) com algumas alterações que se fizeram necessárias, composta dos seguintes itens:

a) Localização e Identificação - Neste item, anotou-se a data em que foi feita a amostragem, o nome da rua na qual o indivíduo está situado, o número do logradouro mais próximo, o nome "comum", a espécie a que pertence o indivíduo em questão, quando possível, e também as dimensões da rua e calçada;

b) Dimensões - Foi mensurado o perímetro na altura do peito (PAP), através da utilização de fita métrica, a altura da primeira ramificação, a altura geral do indivíduo através de estimativa podendo esta ser dividida em três classes sendo pequeno porte (até $5 \mathrm{~m}$ ), médio porte (5 a $10 \mathrm{~m}$ ) e grande porte (acima de $10 \mathrm{~m}$ ), e a área da copa - obtendo as medidas de largura e comprimento e, posteriormente, multiplicando-as;

c) Biologia - Alguns itens relacionados aos aspectos biológicos dos indivíduos analisados foram registrados, de forma visual, de acordo com os critérios a seguir.

Para o estado geral:

- Ótimo - Quando o indivíduo apresentava boa saúde, ausência de injúrias, ataques de insetos - como formigas, cupins ou fungos que possam deteriorar caule e galhos. Neste caso o indivíduo necessita de pouca ou nenhuma manutenção apresentando ótima caracterização da estrutura da espécie.

- Bom - Indivíduo que necessita de manutenção ou reparos, não apresentando estrutura ideal, evidenciando ataques leves de insetos no seu caule e galhos, podendo estar apresentando problemas fisiológicos e doenças diversas.

- Regular - Estado geral ruim, com severos ataques de insetos e fungos, problemas fisiológicos que demandam reparos, além de descaracterização da estrutura da espécie.

- Péssimo - Indivíduo com estrutura severamente descaracterizada, ataques pesados de insetos e fungos, e/ou problemas fisiológicos irreversíveis.

- Morta - Indivíduo seco e sem funcionamento fisiológico.

Foi registrado o equilíbrio geral de cada indivíduo (apresentação do caule retilíneo e copa com proporção igual para ambos os lados). Analisou-se os aspectos associados a fitossanidade, registrando-se o nome popular do indivíduo causador do ataque e a intensidade desses ataques fitossanitários sofridos pelo indivíduo, classificando-se em três níveis: 
- Leve - Quando há presença de agentes, porém sem causar danos aparente ao indivíduo;

- Médio - Presença de danos causados por agentes, no entanto, ainda reversíveis, mediante diferentes tipos de tratamento;

- Pesado - Danos irreversíveis que causaram ou que podem ocasionar a morte eminente do indivíduo.

Local de Ataque: Registra-se a estrutura morfológica do indivíduo que apresenta injúrias e ataques;

d) Entorno e interferências - Local onde o indivíduo está inserido: calçada, canteiro central, praça ou via pública. A localização relativa pode ser classificada ainda como:

- Junto à guia - quando a árvore estiver próxima à guia da calçada;

- Junto à divisa - quando a árvore estiver próxima ao muro;

- Centrada - quando a árvore estiver centralizada na calçada.

Relativamente ao tipo de Fiação, procurou-se identificar de que forma o crescimento do indivíduo afeta ou afetará a fiação, podendo ser primeira via, segunda via, derivação e telefone. A situação pode ser classificada em:

- Atual - quando há galhos tocando a fiação;

- Potencial - que poderá surgir com o crescimento do indivíduo;

- Ausente - quando não há possibilidade de galhos tocarem a fiação.

Foi identificada igualmente a interferência dos indivíduos na iluminação, sinalização e muro/construção, sendo classificados como:

- Atual - quando há interferência de estruturas das árvores em algum desses itens;

- Potencial - quando há possibilidades de ocorrer interferências nesses elementos, pelas estruturas da árvore;

- Ausente - quando não ocorrer interferência de estruturas da árvore.

\section{RESULTADOS E DISCUSSÃO}

Foram inventariados 242 indivíduos arbóreos, distribuídos em 22 espécies e 15 famílias botânicas (Tabela 1). O maior número de árvores encontradas foi de espécies exóticas, perfazendo um total de $63,64 \%$ dos indivíduos avaliados. As espécies nativas representam $36,36 \%$ dessa totalidade. As espécies que apresentaram maior frequência relativa foram Ligustrum lucidum W. T. Ait (45,04\%) e Licania tomentosa (Benth.) Fritsch $(26,45 \%)$, seguidos por Syagrus romanzoffiana (Cham.) Glassman (5,37\%), Ficus benjamina L. (4,96\%), Nectandra megapotamica (Spreng.) Mez. (3,31\%) e Terminalia catappa L. (2,07\%), sendo L. 
lucidum, F. benjamina e T. catappa consideradas espécies exóticas. Os outros indivíduos, somados, representam $12,81 \%$ da amostragem e, individualmente, não atingem $2 \%$.

Tabela 1. Levantamento da flora urbana no bairro Centro, Ibitinga/SP. FA - Frequência absoluta e FR Frequência relativa

Table 1. Survey of urban flora in the neighborhood Centro in Ibitinga/SP. FA - Absolute frequency and FR - Relative frequency

\begin{tabular}{|c|c|c|c|c|c|}
\hline Espécie & Nome comum & Família & Origem & FA & FR \\
\hline Ligustrum Iucidum W. T. Ait & Alfeneiro & Oleaceae & Exótica & 109 & $45,04 \%$ \\
\hline Licania tomentosa (Benth.) Fritsch & Oiti & Chrysobalanaceae & Nativa & 64 & $26,45 \%$ \\
\hline $\begin{array}{c}\text { Syagrus romanzoffiana (Cham.) } \\
\text { Glassman }\end{array}$ & Palmeira Jerivá & Arecaceae & Nativa & 13 & $5,37 \%$ \\
\hline Ficus benjamina L. & Ficus & Moraceae & Exótica & 12 & $4,96 \%$ \\
\hline $\begin{array}{c}\text { Nectandra megapotamica (Spreng.) } \\
\text { Mez. }\end{array}$ & Canelinha & Lauraceae & Nativa & 8 & $3,31 \%$ \\
\hline Terminalia catappa L. & Chapéu de Sol & Combretaceae & Exótica & 5 & $2,07 \%$ \\
\hline $\begin{array}{l}\text { Caelsapina pluviosa DC. var. } \\
\text { peltophoroides (Benth.) G. P. Lewis }\end{array}$ & Sibipiruna & Fabaceae & Nativa & 3 & $1,24 \%$ \\
\hline Cassia fistula L. & Cassia Imperial & Fabaceae & Nativa & 3 & $1,24 \%$ \\
\hline $\begin{array}{c}\text { Dypsis lutescens (H.Wendl.) Beentje \& } \\
\text { J.Dransf }\end{array}$ & Areca Bambu & Arecaceae & Exótica & 3 & $1,24 \%$ \\
\hline Lagerstroemia indica (L.) Pers. & Resedá & Lythraceae & Exótica & 3 & $1,24 \%$ \\
\hline Murraya paniculata (L.) Jack & Falsa Murta & Rutaceae & Exótica & 3 & $1,24 \%$ \\
\hline Schinus molle (L.) & Aroeira Salsa & Anacardiaceae & Nativa & 3 & $1,24 \%$ \\
\hline $\begin{array}{c}\text { Dypsis decaryi (Jum.) Beentje \& } \\
\text { J.Dransf. }\end{array}$ & Palmeira Triângulo & Arecaceae & Exótica & 2 & $0,83 \%$ \\
\hline Plumeria rubra L. & Jasmim-manga & Apocynaceae & Exótica & 2 & $0,83 \%$ \\
\hline Tabebuia $s p$ & Ipê & Bignoniaceae & Nativa & 2 & $0,83 \%$ \\
\hline Bauhinia purpurea (L.) Benth & Pata de vaca & Fabaceae & Exótica & 1 & $0,41 \%$ \\
\hline Callistemon viminalis G. Don ex Loud. & Escova de garrafa & Myrtaceae & Exótica & 1 & $0,41 \%$ \\
\hline Citrus limonum & Limão cravo & Rutaceae & Exótica & 1 & $0,41 \%$ \\
\hline $\begin{array}{c}\text { Cordia americana (L.) Gottshling \& } \\
\text { J.E.Mill. }\end{array}$ & Guajuvira & Boraginaceae & Nativa & 1 & $0,41 \%$ \\
\hline Ixora coccinea L. & Ixora & Rubiaceae & Exótica & 1 & $0,41 \%$ \\
\hline Lagerstroemia speciosa (L.) Pers & Resedá gigante & Lythraceae & Exótica & 1 & $0,41 \%$ \\
\hline $\begin{array}{c}\text { Senna siamea (Lam.) H.S. Irwin \& } \\
\text { Barneby }\end{array}$ & Cássia amarela & Fabaceae & Exótica & 1 & $0,41 \%$ \\
\hline \multicolumn{4}{|c|}{ TOTAL } & 242 & $100 \%$ \\
\hline
\end{tabular}

O número de espécies encontradas no município de lbitinga pode ser considerado baixo comparado a outras cidades, como apontam estudos já realizados em Garça/SP (55 espécies) (NUNES et al., 2013) e Porto Alegre/RS (61 espécies) (SALVI et al., 2011). A semelhança do que foi verificado em Almeida e Rondon Neto (2010), e apesar da legislação e os planos de desenvolvimento urbano não terem sido analisados no presente estudo, os dados aqui obtidos, no leva a acreditar que a baixa quantidade de espécies presentes na arborização 
urbana do bairro Centro, Ibitinga/SP, pode ser entendida como parte de uma falta de planejamento e de legislação para tal finalidade. Isto vai de encontro ao sublinhado por Andreatta et al. (2011) em que poucas cidades brasileiras possuem um planejamento para suas vias públicas.

Kramer e Krupek (2012) apontam que há baixa diversidade de espécies presentes na arborização urbana dos municípios brasileiros, prevalecendo à homogeneização e a valorização de espécies exóticas. Para um programa ideal desse tipo de arborização é necessário que haja diversidade de espécies, tendo em vista maior proteção e controle de pragas e doenças; é recomendado, também, que uma determinada espécie não ultrapasse o valor de $10 \%$ da população total. Em Ibitinga, L. lucidum e L. tomentosa atingem 45,04\% e $26,45 \%$ do total, respectivamente, ultrapassando o valor recomendado. Almeida e Rondon Neto (2010) sublinham que cada espécie não deve ultrapassar $15 \%$ do total de indivíduos da população arbórea, com o intuito de minimizar riscos de pragas e doenças, além de intempéries às quais as espécies possam ser submetidas. A L. lucidum, espécie mais abundante amostrada, é natural do Japão e foi introduzida no Brasil para fins ornamentais, porém é pouco recomendada, pois é considerada uma espécie invasora de alto risco, seus frutos são dispersos por aves e pode atingir áreas naturais nas proximidades (EMER; OLIVEIRA; ALTHAUS-OTTMANN, 2012).

As espécies exóticas representaram $63,64 \%$ do total de indivíduos amostrados e as espécies nativas somaram apenas 36,36\%. Resultados semelhantes, nos quais também predominam a utilização de espécies exóticas foram encontrados no município de Santa Maria/RS (65,89\%) (ANDREATTA et al., 2011).

Segundo Machado et al. (2006), é comum ocorrer nos municípios brasileiros a substituição de flora nativa por plantas exóticas na arborização urbana. Silva et al. (2007) e Blum, Borgo e Sampaio (2008) apontam que a escolha dessas espécies nativas é importante para o planejamento arbóreo, pois espécies exóticas podem causar danos, como a perda de biodiversidade local e alterações nos ciclos dos ecossistemas. Estes autores verificaram que nas áreas amostradas no Paraná, a maioria das espécies identificadas são exóticas e recomendam que sejam gradativamente substituídas por nativas.

A análise de condições gerais dos indivíduos os dividiu em 5 grupos (Figura 2 - A) relacionados ao estado, sendo eles: ótimo, bom, regular, péssimo e morta. Dentro dos 242 espécimes amostrados, apenas 12,4\% apresentavam ótimo estado e 37,6\% apresentaram bom estado, totalizando $50 \%$ dos indivíduos em condições ideais para compor a flora urbana. Já os indivíduos que apresentavam estado geral tido como regular representaram $35,54 \%$, os que foram classificados como em péssimo estado, $13,22 \%$ e os mortos, 1,24\%. A título de comparação, pode-se citar Moura e Santos (2009), que encontraram em Várzea Grande/MT, 
$82 \%$ dos espécimes em boas condições, $16 \%$ registrados como regular e $2 \%$ ruins, indicando que o município de lbitinga, e mais especificamente na área de estudo, necessita de um plano efetivo de manejo para a conservação da sua flora urbana.

A altura média das árvores foi 5,47 metros, com uma distribuição de 103 indivíduos classificados como de pequeno porte (até 5 metros), 133 indivíduos como de médio porte (5 a 10 metros) e apenas 6 espécimes classificados como de grande porte (acima de 10 metros), como pode ser observado na Figura 2 - B.

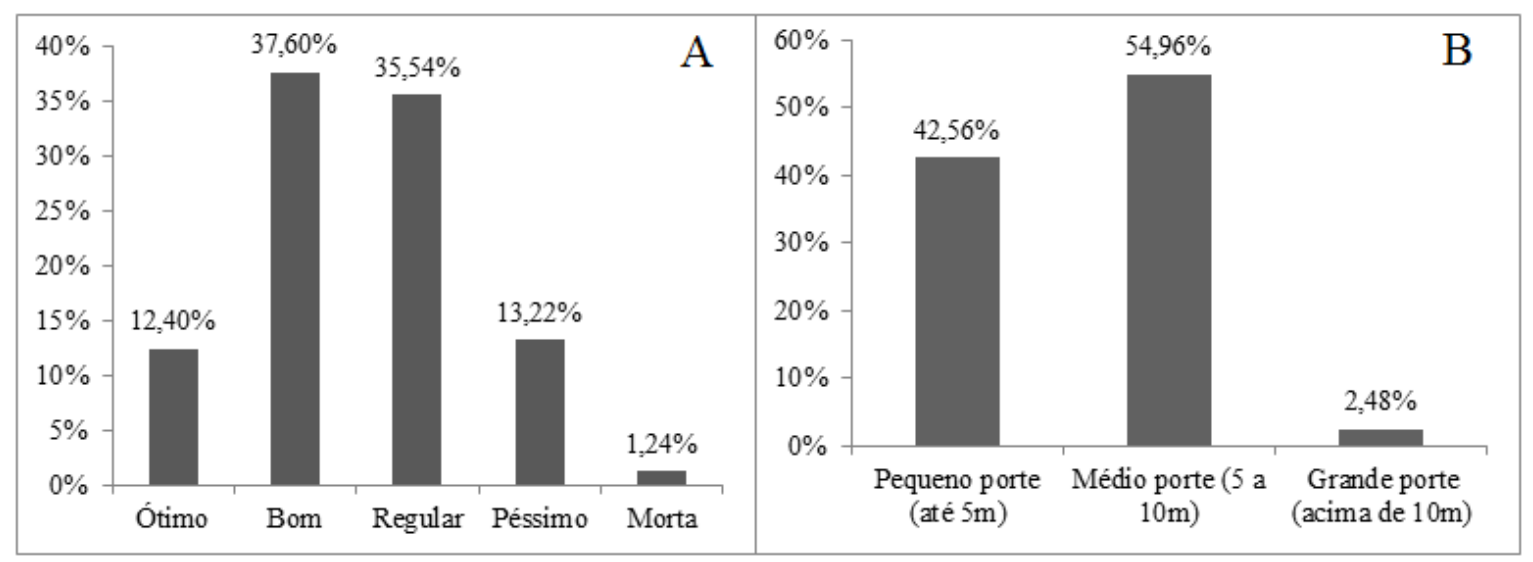

Figura 2. A - Percentual de indivíduos em relação ao seu estado geral; B - Percentual de indivíduos distribuídos de acordo com o porte no bairro Centro, Ibitinga/SP

Figure 2. A - Percentage of individuals in relation to its overall condition; B - Percentage of individuals distributed according to size in the neighborhood Centro in lbitinga/SP

A classe com maior ocorrência foi a II, $54,96 \%$ de todos os indivíduos com destaque para as espécies L. lucidum e L. tomentosa, que atingem este porte arbóreo. A classe I somou $42,56 \%$ do total e a classe III apresentou apenas $2,48 \%$, sendo os representantes desta classe S. romanzoffiana, C. pluviosa e L. speciosa.

O PAP (Perímetro à Altura do Peito) médio foi de $63 \mathrm{~cm}$. A menor medida foi de $13 \mathrm{~cm}$ e a medida máxima foi de $210 \mathrm{~cm}$. Os indivíduos puderam ser divididos em 4 classes para o PAP conforme demonstrado na figura 3. 


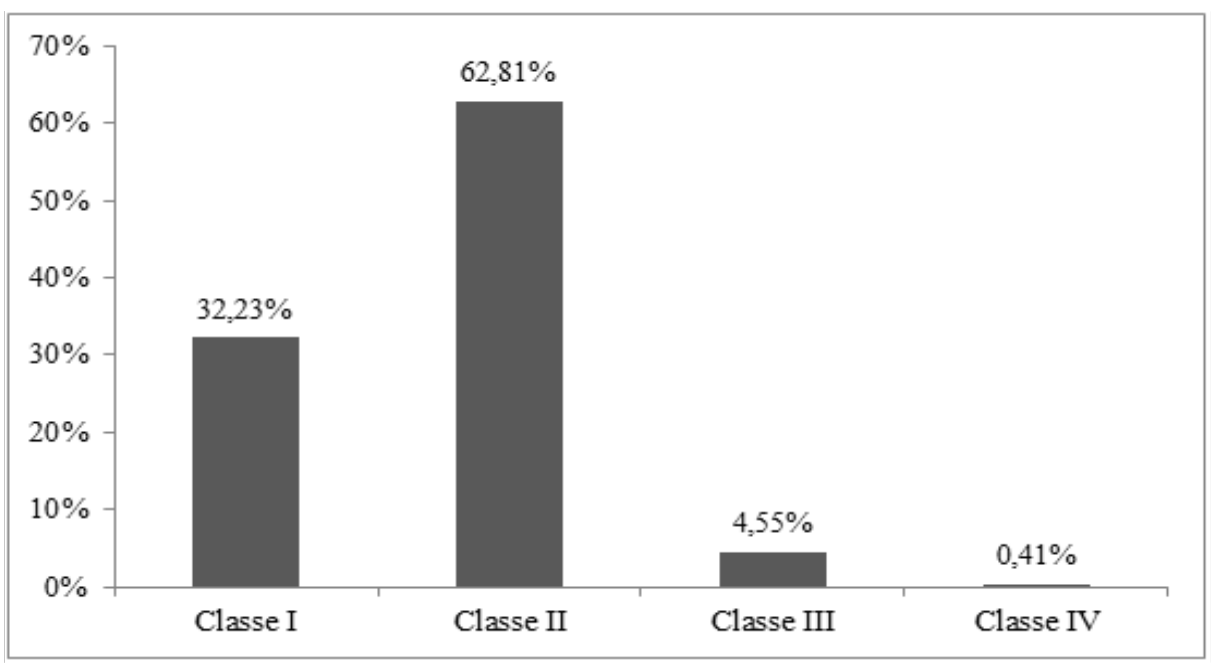

Figura 3. Relação de classes de PAP. Sendo: Classe I (0,01 a 0,50m), Classe II (0,51 a 1,00m), Classe III (1,01 a $1,50 \mathrm{~m})$ e Classe IV (maior que $1,51 \mathrm{~m}$ ), no bairro Centro, Ibitinga/SP

Figure 3. List of PAP classes. In which: Class I $(0.01$ to $0.50 \mathrm{~m})$, Class II (0.51 to $1.00 \mathrm{~m})$, Class III (1.01 to $1.50 \mathrm{~m}$ ), and Class IV (greater than $1.51 \mathrm{~m}$ ) in the neighborhood Centro in lbitinga/SP

Relativamente as dimensões dos indivíduos, a análise das classes de PAP possibilitou verificar que não houve relação com a média da altura e formação de copa por conta de podas constantes. A classe com maior expressão foi a classe II, evidenciando uma população de indivíduos em sua grande parte já adultos. Esta análise torna-se pertinente devido a todas as espécies sofrerem basicamente o mesmo tipo de poda e não se respeitando a estrutura natural de cada uma.

A altura da primeira ramificação é descrita como ideal com, no mínimo, 1,8m de altura (GONÇALVES et al., 2004), entretanto, foram identificados $60,74 \%$ da população com altura menor do que o mínimo recomendado e apenas 39,26\% com altura ideal para a primeira ramificação. Esses resultados podem indicar a falta de poda de condução e plantio de mudas inadequadas, além de evidenciar que a presença de ramificações abaixo de 1,8 $\mathrm{m}$ pode dificultar o livre passeio dos pedestres, gerando possíveis transtornos aos transeuntes. Segundo Almeida e Rondon Neto (2010), a alta concentração de indivíduos na primeira classe de altura de bifurcação do tronco, em duas cidades do Mato Grosso avaliadas, pode ser um indicativo da baixa qualidade das mudas utilizadas na arborização urbana, que pode ser atribuída ao fato de os plantios nessas cidades serem realizados pelos próprios moradores, sem haver preocupação com aspectos técnicos.

Do total de exemplares amostrados, apenas 17,36\% não apresentaram nenhum desequilíbrio de caule ou copa. Em contrapartida, 82,64\% dos exemplares evidenciaram alguma oscilação - sendo que 23,5\% apresentaram apenas desequilíbrio de copa, $21 \%$ desequilíbrio de caule e em 55,5\% foram constatados ambos os desequilíbrios. O número de indivíduos que apresentaram desiquilíbrios é elevado, chegando a $82,64 \%$ da população e 
destes, $79 \%$ apresentaram o caule em desacordo com o recomendado, que é descrito como ideal ser retilíneo e ereto. Para a arborização urbana é fundamental a presença de espécimes com caule retilíneo, pois caules que apresentam tortuosidades podem dificultar o passeio público pela calçada e também elevar o risco de queda. De acordo com Lima Neto et al. (2010), a tortuosidade presente no caule pode ocorrer pela ausência de manejo, problemas na condução e no tutoramento das plantas ainda no estágio de mudas.

Apenas $31,82 \%$ dos indivíduos da amostra estavam isentos de qualquer tipo de infestação parasitária e 68,18\% portavam alguma infestação (Figura 4). Dentro da classificação para os ataques fitossanitários, foram identificados como tendo sido acometidos por ataques leves, 38,18\%, por ataques médios, $44,85 \%$ e por ataques pesados, $16,97 \%$. O local de ataque de maior frequência para infestação de pragas foram os ramos $(56,97 \%)$, em maior parte, por fungos que estavam presentes em galhos senis, seguido de $26,06 \%$ de indivíduos infestados apenas no caule, $15,55 \%$ com danificações presentes no caule e nos ramos e $2,42 \%$ com ocorrências de ataques nas folhas. As infestações parasitárias podem estar ligadas à menor riqueza vegetal em áreas urbanas, visto que o baixo número de espécies pode facilitar a propagação de pragas e doenças parasitárias entre as árvores. O mesmo não acontece com tanta frequência em áreas nativas como constatado por Sulevis e Biondi (2014) com a erva-depassarinho nas ruas de Curitiba.

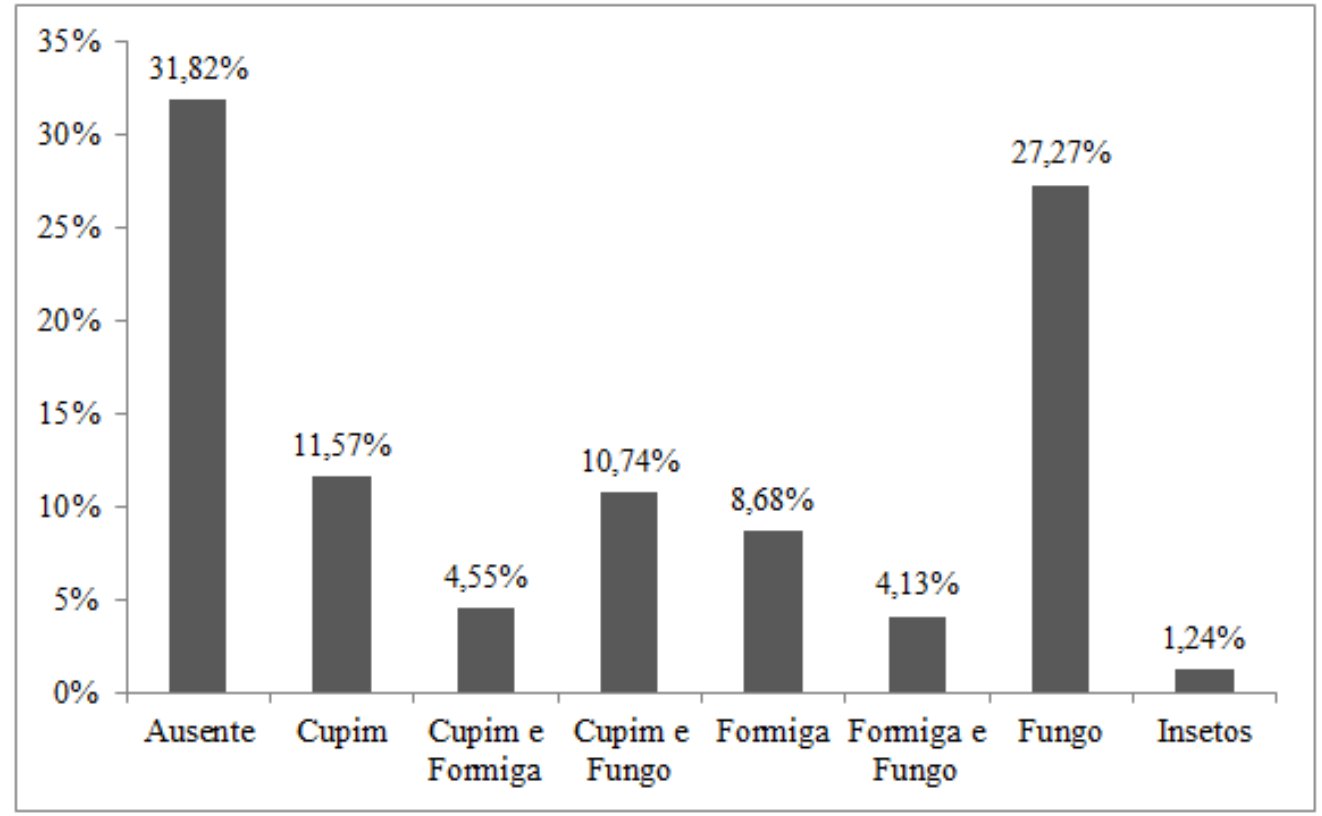

Figura 4. Percentual de infestações nos exemplares inventariados no bairro Centro, Ibitinga/SP Figure 4. Infestation percentage in inventoried specimen in the neighborhood Centro in Ibitinga/SP

A análise do entorno e de possíveis interferências para o desenvolvimento arbóreo apontou que $31,82 \%$ da população amostrada já apresentava conflito com a rede aérea e que 
$12,81 \%$ possuíam potencial para o crescimento e, consequentemente, surgimento desse conflito. Damo, Hefler e Jacobi (2015) encontraram maior percentual em uma pesquisa na cidade de Rio Grande (RS), onde $52,3 \%$ de sua população era conflitante com essa rede. Estes números indicam o não planejamento adequado para a arborização urbana visto que não são seguidos critérios técnicos para escolha das espécies. Uma parcela de 5,37\% apresentou conflitos com muros e postes de iluminação e não foi encontrado nenhum espécime que apresentasse conflito com a iluminação pública. Constatou-se, também, que $4,55 \%$ dos indivíduos obstruíam a visibilidade de placas de trânsito e que 17,77\% da amostra possuía conflitos com muros e construções havendo, ainda, $43,39 \%$ de espécimes com potencial para 0 mesmo.

\section{CONCLUSÕES}

A arborização viária do bairro Centro do município de Ibitinga/SP apresenta baixa diversidade, frequência de espécies irregulares e uso excessivo de plantas exóticas. A maior frequência foi de L. lucidum, árvore originária da Ásia que, apesar de seu potencial paisagístico, não é recomendada para arborização, pois é considerada invasora para os ecossistemas nativos sendo indicada a substituição da mesma.

Sobre a infestação parasitária, foi encontrado um número inferior a $50 \%$ da população isenta de parasitas, evidenciando assim que grande parte da população amostrada não apresenta condições ideais para compor a flora urbana.

Observaram-se conflitos com a rede aérea devido ao uso de espécies de porte elevado abaixo da fiação, indicando falta de planejamento e ausência de critérios técnicos para composição da flora urbana.

\section{AGRADECIMENTOS}

Os autores agradecem a Leila Maria Gumushian Felipini e dois avaliadores anônimos pelas preciosas contribuições ao manuscrito. 


\section{REFERÊNCIAS}

ALMEIDA, D. N.; RONDON NETO, R. M. Análise da arborização urbana de duas cidades da região norte do estado de Mato Grosso. Revista Árvore, Viçosa, v. 34, n. 5, p. 899-906, 2010.

ANDREATTA, T. R.; BACKES, F. A. A. L.; BELLÉ, R. A.; NEUHAUS, M.; GIRARDI, L. B.; SCHWAB, N. T.; BRANDÃO, B. S. Análise da arborização no contexto urbano de avenidas de Santa Maria, RS. Revista da Sociedade Brasileira de Arborização Urbana, Piracicaba, v. 6, n. 1, p. 36-50, 2011.

BLUM, C. T.; BORGO, M.; SAMPAIO, A. C. F. Espécies exóticas invasoras na arborização de vias públicas de Maringá - PR. Revista da Sociedade Brasileira de Arborização Urbana, Piracicaba, v. 3, n. 2, p. 78-97, 2008.

CARDOSO-LEITE, E.; FARIA, L. C.; CAPELO, F. F. M.; TONELLO, K. C.; CASTELLO, A. C. D. Composição florística da arborização urbana de Sorocaba/SP, Brasil. Revista da Sociedade Brasileira de Arborização Urbana, Piracicaba, v. 9, n. 1, p. 133-150, 2014.

CENTRO DE PESQUISAS METEOROLÓGICAS E CLIMÁTICAS APLICADAS À AGRICULTURA (CEPAGRI). Clima dos Municípios Paulista. Disponível em: <http://www.cpa.unicamp.br/outras-informacoes/clima-dos-municipios-paulistas.html> Acesso em: 12 nov. 2015.

DAMO, A.; HEFLER, S. M.; JACOBI, U. S. Diagnóstico da arborização em vias públicas dos bairros Cidade Nova e Centro na cidade de Rio Grande/RS. Revista da Sociedade Brasileira de Arborização Urbana, Piracicaba, v. 10, n. 1, p. 43-60, 2015.

EMER, A. A.; OLIVEIRA, M. C.; ALTHAUS-OTTMANN, M. M. Biochemical composition and germination capacity of Ligustrum lucidum Ait. seeds in the process of biological invasion. Acta Scientiarum, Maringá, v. 34, n. 3, p. 353-357, 2012.

ESTADO DAS CIDADES DA AMÉRICA LATINA E DO CARIBE. Disponível em: http://www. es.unhabitat.org. Acesso em: 09 jul. 2017.

FARIA, R. F.; SOUSA, V. R.; MIRANDA, S. C. Arborização urbana da cidade de Itapuranga, Goiás. Revista da Sociedade Brasileira de Arborização Urbana, Piracicaba, v. 9, n. 2, p. 101-117, 2014.

GONÇALVES, E. O.; PAIVA, A. N.; GONÇALVES, W.; JACOVINE, L. A. G. Avaliação qualitativa de mudas destinadas à arborização urbana no Estado de Minas Gerais. Revista Arvore, Viçosa, v. 28, n. 4, p. 479-486, 2004.

INSTITUTO BRASILEIRO DE GEOGRAFIA E ESTATÍSTICA - IBGE. Disponível em: $<$ http://www.cidades.ibge.gov.br/painel/painel.php?lang=\&codmun=351960\&search=s\%E3opaulo\%7Cibitinga >. Acesso em: 09 jul. 2017.

KRAMER, J. A.; KRUPEK, R. A. Caracterização florística e ecológica da arborização de praças públicas do município de Guarapuava, PR. Revista Árvore, Viçosa, v. 36, n. 4, p. 647-658, 2012.

LIMA NETO, E. M.; BARDELLI da SILVA, M. Y.; SILVA, A. R.; BIONDI, D. Arborização de ruas e acessibilidade no bairro centro de Curitiba - PR. Revista da Sociedade Brasileira de Arborização Urbana, Piracicaba, v. 5, n. 4, p. 40-56, 2010. 
LIMA NETO, E. M.; BIONDI, D. Delineamento de unidades amostrais para o inventário da arborização de ruas em Curitiba, PR. Revista da Sociedade Brasileira de Arborização Urbana, Piracicaba, v. 9, n. 1, p. 21-34, 2014.

MACHADO, R. R. B.; MEUNIER, I. M. J.; SILVA, J. A. A.; CASTRO, A. Árvores nativas para a arborização de Teresina, Piauí. Revista da Sociedade Brasileira de Arborização Urbana, Piracicaba, v. 1, n. 1, p. 10-18, 2006.

MUNEROLI, C. C.; MASCARÓ, J. J. Arborização urbana: uso de espécies arbóreas nativas na captura do carbono atmosférico. Revista da Sociedade Brasileira de Arborização Urbana, Piracicaba, v. 5, n. 1, p. 160-182, 2010.

MOURA, T. A.; SANTOS, V. L. L. V. Levantamento quali-quantitativo de espécies arbóreas e arbustivas na arborização viária urbana dos bairros Centro e Centro Norte, Várzea Grande, Mato Grosso, Brasil. Revista da Sociedade Brasileira de Arborização Urbana, Piracicaba, v. 1, n. 1, p. 97-117, 2009.

NUNES, R. L.; MARMONTEL, C. V. F.; RODRIGUES, J. P.; MELO, A. G. C. Levantamento qualiquantitativo da arborização urbana do bairro Ferraropólis na cidade de Garça - SP. Revista da Sociedade Brasileira de Arborização Urbana, Piracicaba, v. 8, n. 1, p. 65-74, 2013.

ROCHA, R.T.; LELES, P.S.S.; OLIVEIRA NETO, S. N. Arborização de vias públicas em Nova Iguaçu, RJ: o caso dos bairros Rancho Novo e Centro. Revista Árvore, Viçosa-MG, v. 28, n. 4, p. 599-607, 2004.

SALVI, L. T.; HARDT, L. P. A.; ROVEDDER, C. E.; FONTANA, C. S. Arborização ao longo de ruas - túneis verdes - em Porto Alegre, RS, Brasil: avaliação quantitativa e qualitativa. Revista Árvore, Viçosa, v. 35, n. 2, p. 233-242, 2011.

SANTOS, A. F.; JOSÉ, A. C.; SOUSA, P. A. de. Fitossociologia e diversidade de espécies arbóreas das praças centrais do município de Gurupi-TO. Revista da Sociedade Brasileira de Arborização Urbana, Piracicaba, v. 8, n. 4, p. 36-46, 2013.

SILVA FILHO, D. F. da; PIZETTA, P. U. C.; ALMEIDA, J. B. S. A. de; PIVETTA, K. F. L.; FERRAUDO, A. S. Banco de dados relacional para cadastro, avaliação e manejo da arborização em vias públicas. Revista Árvore, Viçosa, v. 26, n. 5, p. 629-642, 2002.

SILVA, L. M.; HASSE, I.; MOCCELIN, R.; ZBORALSKI, A. R. Arborização de vias públicas e a utilização de espécies exóticas: o caso do bairro Centro de Pato Branco-PR. Revista Scientia Agraria, v. 8, n. 1, p. 47-53, 2007.

SHAMS, J. C. A.; GIACOMELI, D. C.; SUCOMINE, N. M. Emprego da arborização na melhoria do conforto térmico nos espaços livres públicos. Revista da Sociedade Brasileira de Arborização Urbana, Piracicaba, v. 4, n. 4, p. 1-16, 2009.

SULEVIS, C.; BIONDI, D. Análise morfológica de espécies da arborização de ruas de CuritibaPR e a infestação por erva-de-passarinho. Revista da Sociedade Brasileira de Arborização Urbana, Piracicaba, v. 9, n. 2, p. 1-17, 2014. 